\title{
A Sustainable Governmental Intervention Policy for Slum Upgrading: Road Infrastructure in Railway Down Quarter, Kaduna, Nigeria
}

\author{
Suleiman Iliya, Assoc.Prof.Dr. Huriye Gürdallı ${ }^{1}$
}

\begin{abstract}
The urban cities in Nigeria are experiencing a deformation causing an urban decay with poor housing construction, improper use of unplanned land hindering urban spatial development. In this paper examination of slum prevalence in Nigeria and aims to propose development scheme to improve informal settlement of the urban cities focusing on governmental intervention and development policies in all level of governmental authorities to upgrade the living conditions and obtain value for the urban low class. Harvesting the potential of the work force of this regions for urban development, aims to provide highlight to the use of infrastructural development particularly road network to aid connectivity and urban design. A review of informal settlement mainly on the absence of infrastructure and degraded environmental conditions in an unplanned settlement in the city of Kaduna popularly known as Railway Down Quarter, proposes a possible strategy and approach for a sustainable upgrading policy. This research develops a conceptual approach of the necessity of mainly road infrastructure a medium that introduces services and a sustainable development in informal settlements in Kaduna, Nigeria by government intervention.
\end{abstract}

Keywords: Slum upgrade, government policy, road infrastructure, Railway Down Quarter, Kaduna, Nigeria

\section{Introduction}

Viewing at the emerging process of Kaduna city from the colonial period to this day it can be said that it is an industrial city of Nigeria that has grown and will continue in the foreseen future which direct our attention to the urban planning reforms of the developing land areas that occupy a large number of unplanned settlements. Studies has shown us progressive development of the urban city to the time of the colonial masters and their environment in terms of land organization and house planning by the utilization of infrastructural aid to plan cities with the provision of well layout of roads, spacing which forms a system of well-planned urban arrangements. However after the colonial era development started in the city from the 1970s with industrial activities that attracted the rural population leading to migration and increase in unprofessional workers who resorted to settle on unplanned land with as they are more of low income population. Industrialization brought about increase in urban poor population causing the emergence of slum habitats.

Railway Down Quarter is a settlement in the city of Kaduna that emerged gradually along the years. It is located at an area called Makera in the southern part of Kaduna that has experienced a fair share of industrial activities as it emerges around companies like 
the Nigerian textile limited, Nigerian breweries plc and Nigerian bottling company. This settlement emerged along the railway lines that has been dysfunctional in recent time and abandoned at the same time the increase of illegal settlement by immigrants on open lands and railways workers building led to the informal settlement pattern and the construction of shanty structures in this community. Most of the settlers in this area are traders that involve in commercial activities around the train station located in the region. Railway Down Quarter has been in existence from the year 1900 when the railway stations was established which was Nigerians most efficient means of transporting agricultural goods for exports by the foreign expatriates from northern Nigeria to Lagos state of Nigeria. It is said to be the biggest station in the state of Kaduna and because of that it is popularly known as Rail way Down Quarter. The occupation of the people in this area are mostly traders, civil servants and farmers.

\section{Geographical features and demography}

\subsection{Location of Railway Down Quarters in Kaduna}

This review focuses on the history of Kaduna state and its development from its inception when the British colonial administration named it the seat of the Northern Protectorate in 1912 by the led by Lord Frederick Lugard during the Independence and post-independence period, when Kaduna became the capital of the northern Nigeria region and now holds the status of the capital of the state of Kaduna. This write up also highlights the demographic factors and the changes that have taken place in Kaduna over the years and urban planning policies and innovations that have molded its evolved urban form and environment by also emphasizing the importance of Kaduna as one of the Nigerian states that has experienced the effect of industrialization that has led to migration from rural to urban areas due to industrial activities. Finally, the challenges facing the city today are critically analyzed as well as recent government initiatives to address these challenges.

To date, Kaduna can be said to still be the political capital city of Northern Nigeria, as crucial matters of state, especially those affecting the Northern region are discussed by Northern state governors in Kaduna. So also do Northern traditional rulers meet in Kaduna to discuss matters under their areas of responsibility. Indeed, as mark of the centrality of Kaduna in the political economy of Nigeria, it is said that when Kaduna sneezes, the rest of the country catches cold. Owing to this attribute, and as a point of relatively higher economic concentration, compared to all other cities in the North, excepting Kano, it can be safely said that Kaduna is very much a part of the national and global financial flows. This is evident in the visible growth of investment in real estate in the city (Etham, 2012).

In the map of Kaduna as seen in Figure 1 the river Kaduna stand as the element that shows a an spatial geographical expansion in respect to the state development. 


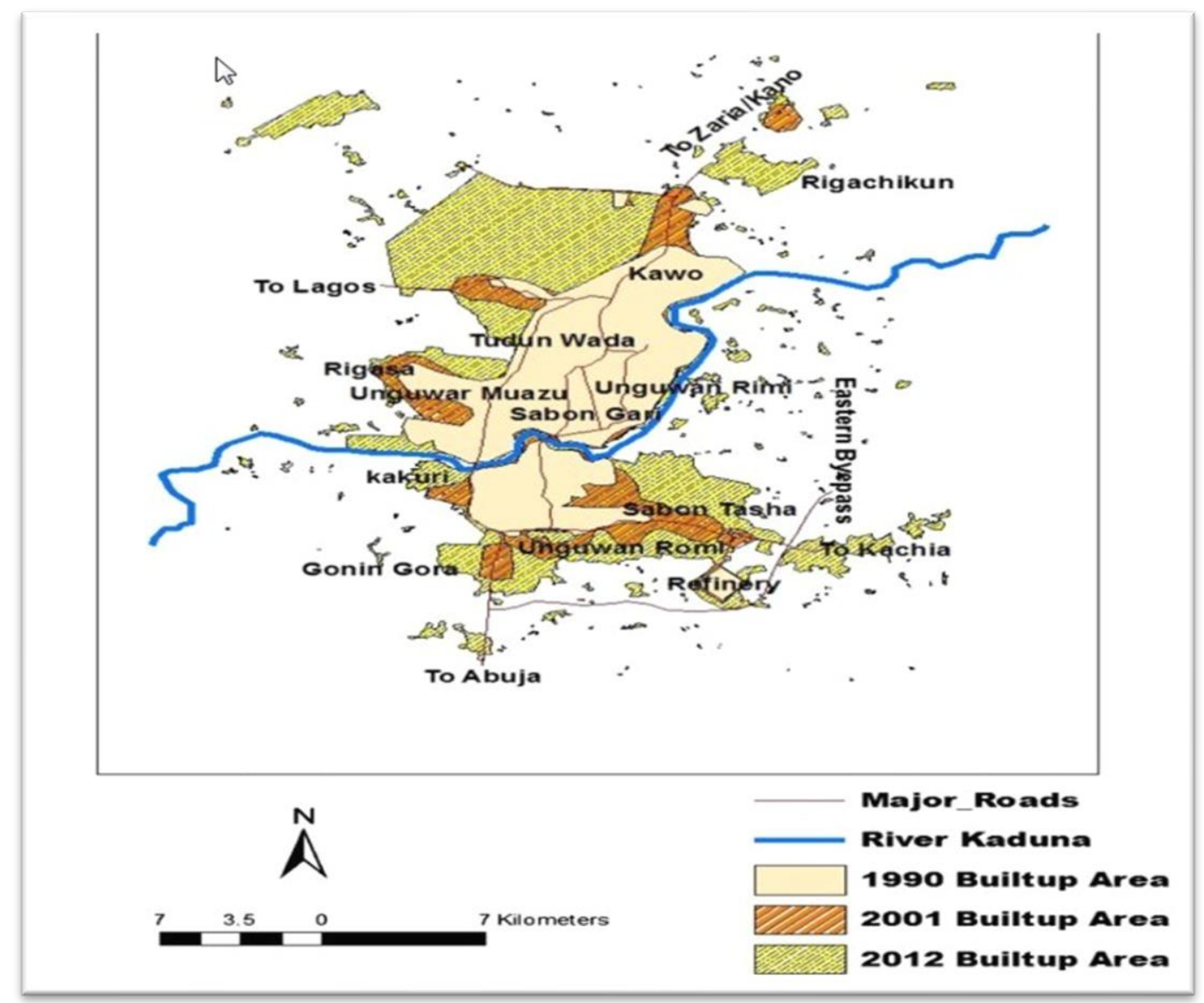

Figure 1: Spatial extent of Kaduna (Bununu, 2015)

Railway Down Quarter is a slum In the Makera ward in Kaduna south local government, Kaduna State Nigeria. The community is located at the S.E of the Kaduna topographical map, seated along the river side of river Kaduna floodplain, leading most of this floodplains to be converted into built-up areas as a result of population outburst which is brought about by factors like urbanization and work opportunities from the early 70 s till date. 


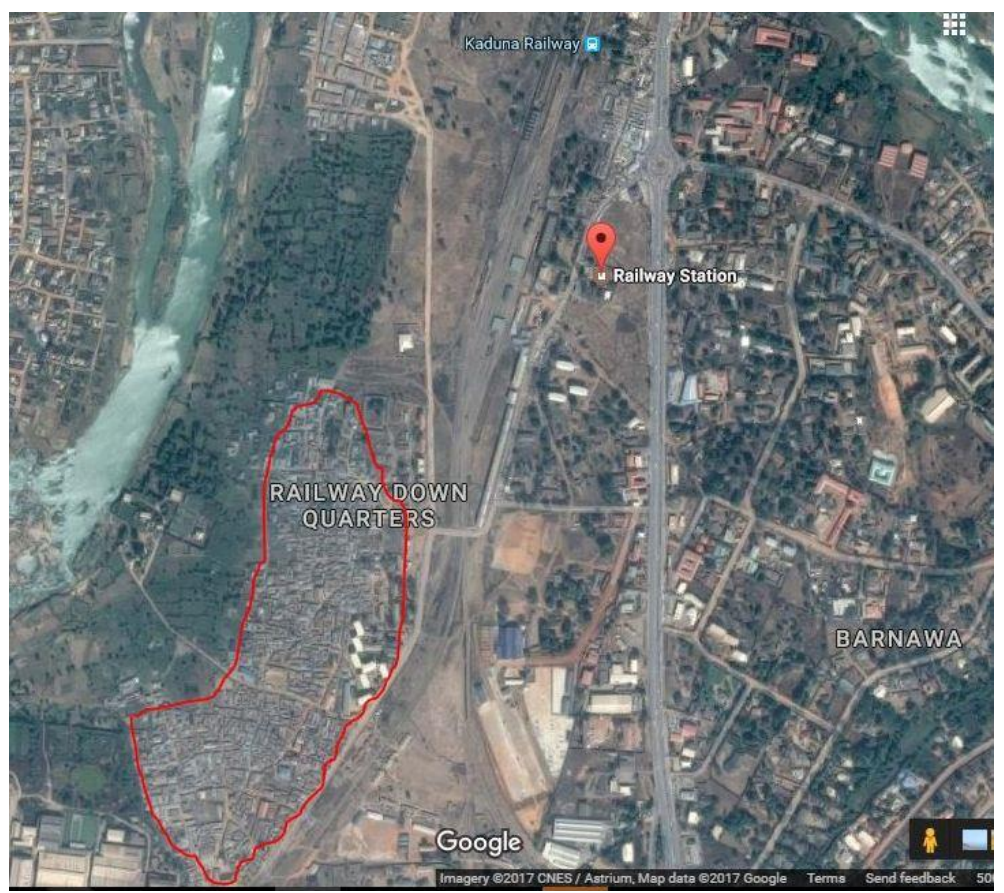

Figure 2: Down Quarter slum Makera, Kaduna (Elaboration by the author on the Google earth map, 2017)

The location of Railway Down Quarter as shown in (Figure 2) is approximately $2 \mathrm{~km}$ south west of the Rail Way station, position on the open lands along the river side and also along the rail way tracks which have been abandoned and damaged as a result of no maintenance and government negligence along the years.

The Rail Way Station and most of its immediate surrounding are government lands that contain assets of the state government which makes it an inhabitable location for any form of settlement by informal settlers, leading to the prevalence of informal settling along the flooded plain lands along the river side as it is open green land that can be habituated. The train station terminal of Kaduna State located approximately $2 \mathrm{~km}$ from the Down Quarter settlemnet where the station has not been in use since 1990 


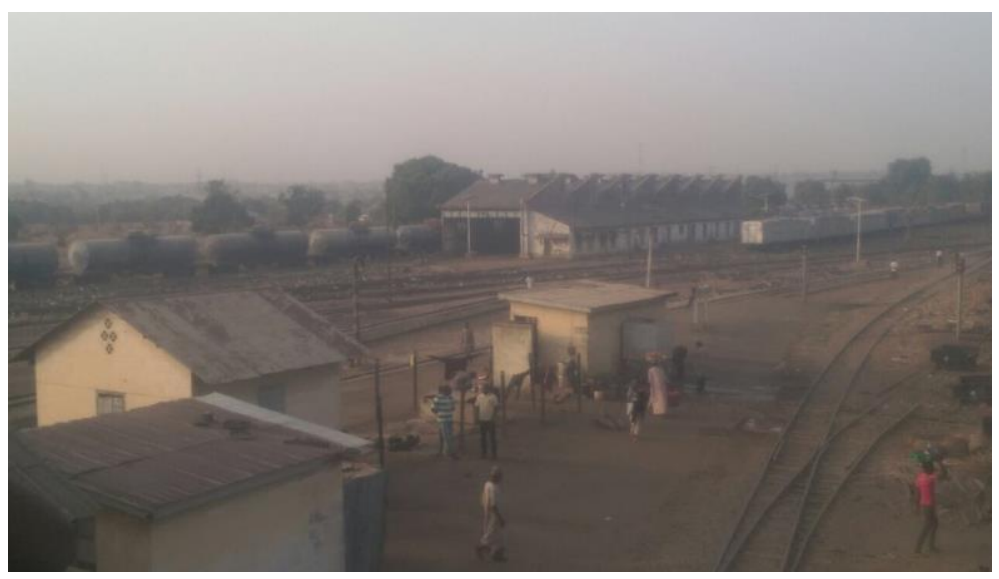

Figure 3. Train Station Assets (liiya, 2017)

The image seen in Figure 3. shows the train station assets surrounding the rail way station with service docks, train carriers, maintenace station and connecting terminals which make it inhabitable for any form of settlement.

\subsection{Demography}

Along the years it has witnessed an increase in population growth mainly from rural urban migration. Railway Down Quarters is a settlement that is surrounded with a handful of industrial activities has owned a great share of rural settling in the city of Kaduna. Railway Down Quarters is estimated to have a population of about 130,000 increasingly. The NPC (Nigerian Population Commision) has gathered a progressive recording on how population has increased in subsequent years.

Table 1. Population figures of localities along River Kaduna Plain (NPC, 2006)

\begin{tabular}{|l|l|l|l|l|l|}
\hline LOCALITIES & $\mathbf{1 9 9 1}$ & $\mathbf{1 9 7 6}$ & $\mathbf{1 9 8 7}$ & $\mathbf{1 9 9 5}$ & $\mathbf{2 0 1 0}$ \\
\hline Rafin Gusa & 19,658 & 12,286 & 17,692 & 21,820 & 31,395 \\
\hline Malali & 22,677 & 14,173 & 20,409 & 25,171 & 36,217 \\
\hline Kabala Doki & 22,694 & 14,184 & 20,425 & 25,190 & 36,244 \\
\hline Narayi & 23,674 & 14,796 & 21,307 & 26,278 & 37,808 \\
\hline Makera & 77,374 & 48,359 & 69,637 & 85,885 & 123,572 \\
\hline Barnawa & 32,684 & 20,428 & 29,416 & 36,279 & 52,198 \\
\hline Narayi & 23,674 & 14,796 & 21,307 & 26,278 & 37,808 \\
\hline
\end{tabular}

In subsequent years population has increased from the year of industrial boom in the country as shown on Table 5.1, indicates that along the years from the the period of industrial growth (1970s), there has been an increase in population with immigrants from the rural areas as most of the settlers in this community consists of tribe from the different part of Nigeria converging on a piece of land. Most of the settlers in this community are farmers, traders and old retired railway workers. 


\section{Communal and environmental aspects}

Railway Down Quarter is a densely compacted settlement of mainly shanty constructed building with the purpose of housing for habitats both permanently and temporary intended, however there is no common space available for socializing and interaction in this compacted habitat as space is most open spaces are regarded as possible settlement spots of informal constructed homes. Habitats are subjected to the use of social environment in the urban grid closer to them, around the train station such as markets, mosques, churches and areas for ceremonial gathering. It can be said that the settlement has no common ethnicity as it is inhabited with people from different cultures and religion.

Station Market (Figure 4) as popularly known is a busy market around the train station, it is one of the market in the urban city mostly appreciated for vegetables and food material. The market serves as a public area for commerce in the urban city close to Down Quarter settle of about 3km away, most of the traders in this market are habitants of Railway Down Quarters. In the sense that the Railway Down Quarter has no general market located in the area, habitats of the informal settlement refer to this market for most of their commercial activities of buying and selling.

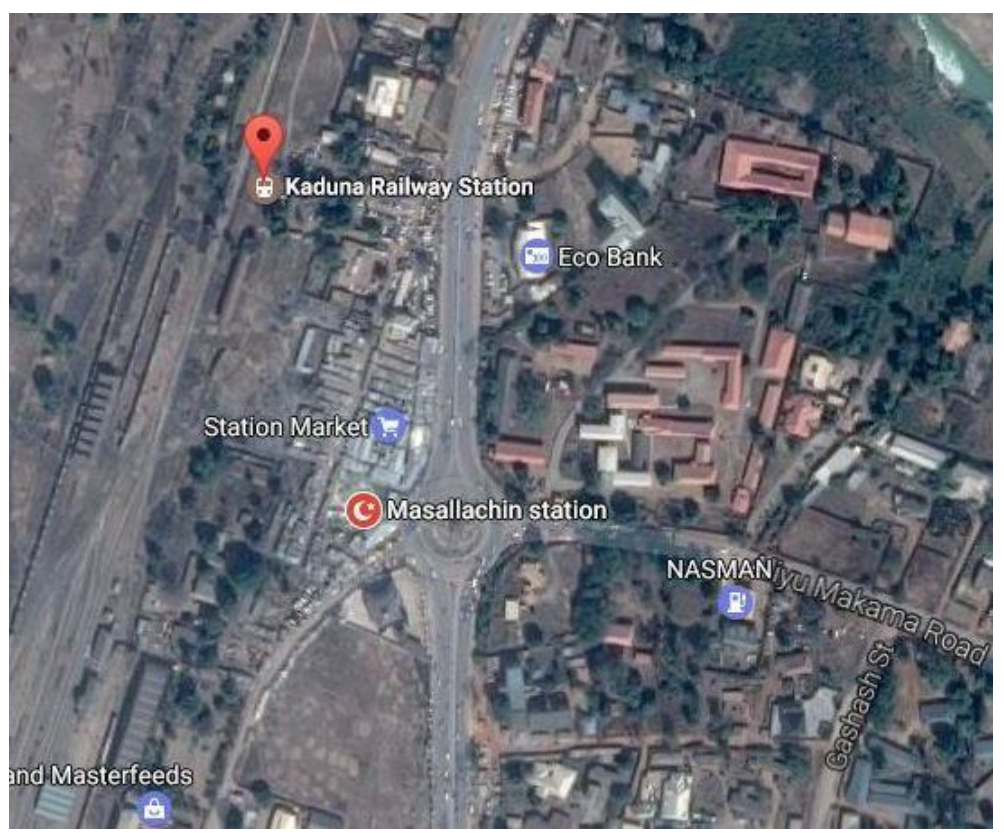

Figure 4: Station Market and Masallachin Station Mosque (Elaboration by the author on the Google earth map, 2019)

However in this settlement, small scale home businesses are common amongst the settlers where pity items are been sold in from home in a small scale but not as a major market provision avenue for interaction and trade activities. 


\subsection{Environmental indicators}

The community of Down Quarter is characterized by its shanty constructed shelters along railway lines and lack of space which lead to congestion and inadequate drainage provision. Refuse are dumped out in open areas and the sanity condition of the community can be said to be very hazardous to the health of the habitant.

Slum habitat are characterized with the emergence of certain entities such as inadequate access to water, inadequate sanitation, infrastructural amenities and poor structural quality in housing(UN Habitat, 2012). The prevalence of this informal housing pattern along the years has led to the development of a slum habitat as it is characterized by overcrowding, poorly constructed shelters, little or no infrastructure, poor sanitary conditions for living and poor integration with the urban city in terms of accessibility. The informal settlements including slums that has been developed as a result of rapid urbanization process, they tend to provide the residents with the same services and economic facilities (Jones, 2017). In the case of this research analysis and evaluation of the standard of living will be conducted by the condition and sustainable factors which helps us to classify a habitat to be called a slum and its inadequate standards.

Given the characteristic by UN habitat, it can relate the settlement of Down Quarter in the Southern Kaduna district to be a habitat that interprets the settlement as a slum area, as images shown to apply the points on.

\subsection{Sanitary indications}

The absence of a standard sanitary care system in the community, refuse disposal and drainage systems are needed to control litter and drainage products, these byproducts are spread all over the environment causing multiple pollutions which leads to the occurrence and spread of different sort of diseases.

Public open space that can aid community development and settlers cohesive relationship is not available as they are little spaces between house and no common area for communal interaction.

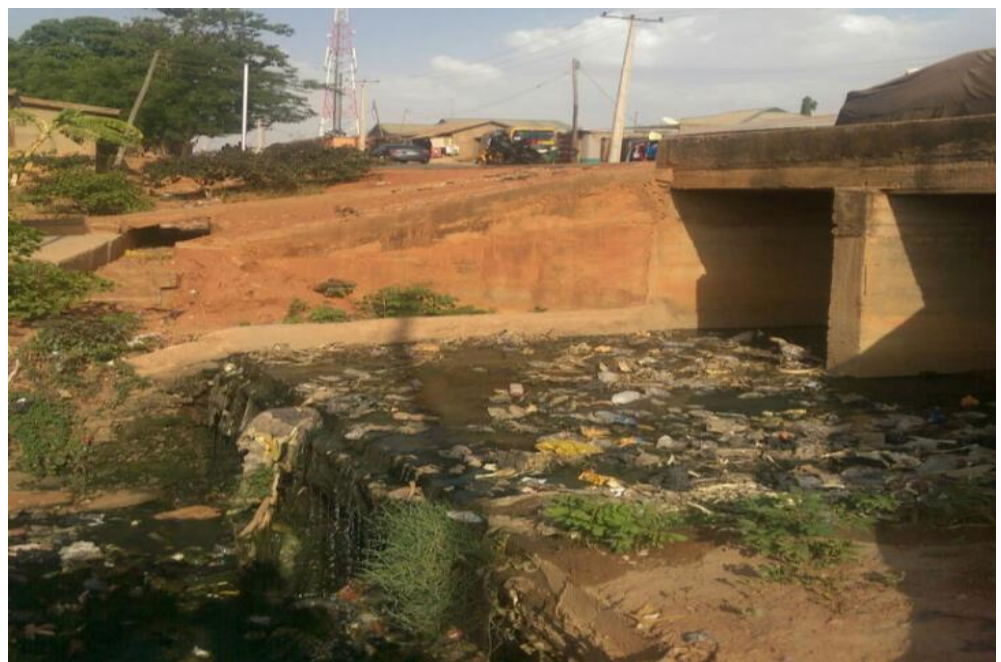

Figure 5: Drainage System. Source (Iliya, 2017) 
Figure 5 shows the drainage system from the urban city of industries and factories around the settlement being littered from the settlement of Down Quarter.

\subsection{Housing design and material}

The construction of shanty homes with low standard materials is shown in the image (Fig 6), these are not spatial distributed in an arranged manner, show little or no road access to certain locations. Congested spaces are also seen as which reduces level of ventilation and adds the spread of diseases. The indication of poor house design and use of inadequate materials is the manner of construction in this settlement, only few dwellers have the capacity to build adequate structures and environment. Though windows and doors are constructed it has little effect as the buildings are congested together without space for adequate ventilation. Considering the climatic factor as it can get as hot as 43 degrees and the heavy rainfall in Kaduna, standard construction method should be adhered.

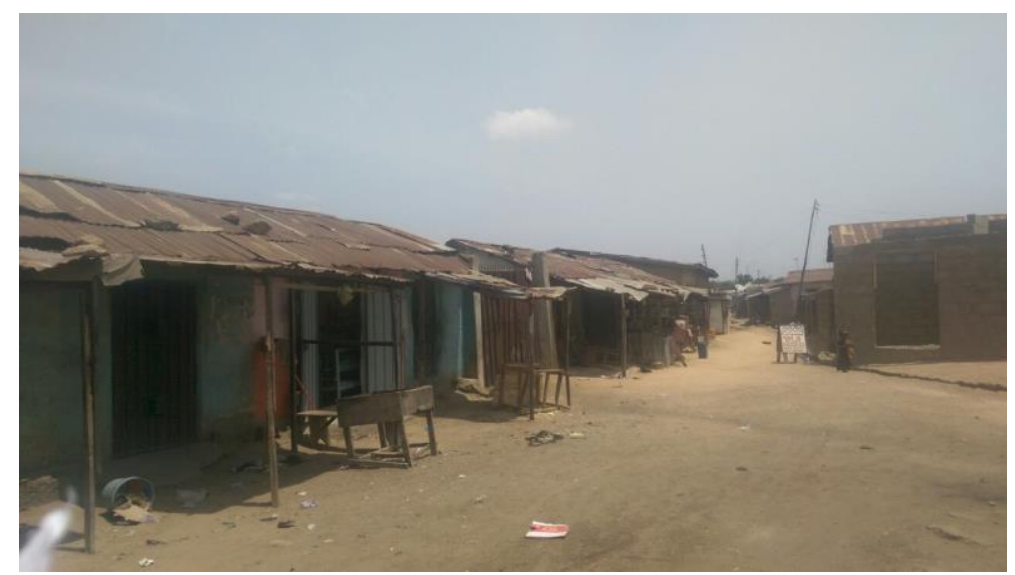

Figure 6: Housing in Down Quarter (Iliya, 2017)

The construction of home in this settlement as shown in Figure 7. shows the pattern and type of materials used in the development of shanty homes with the use of low standard methods and materials. Homes are constructed with materials that are weak and have low resistance to hazardous factors. The use of wood, zinc are commonly used in this settlement and also the use of standard opening for ventilation is not carried out in the construction of this shanty homes.

\section{A Sustainable Governmental Policy for Intervention \\ 4.1 Government Provided Facilities}

Most of the social amenities available in this slum community was provided by the railway cooperation until 1990s when democracy was introduced back to Nigeria, since then settlers has forwarded their needs to the government through community heads. Some of these needs were provided such as primary school, a health care facility and borehole water. The government has promised to provide hospital, roads, secondary 
schools and improve their drinking water and other amenities that will make their life better but all to no effect till now (Figure 7).

In an interview with the chief of Down Quarter by the name Alh Danjuma Mohammed Musa on the $24^{\text {th }}$ July 2016, it was discussed that the population of 130,000 people living with little or no social amenities but however consist of one primary school, one health facility and one borehole for water supply, one police station and a football field. Down Quarter has no open space for movement and direct accessibility to the urban city which are the challenges facing the community, no higher institution also and the habitats of this community are from various tribes and religion across the country.

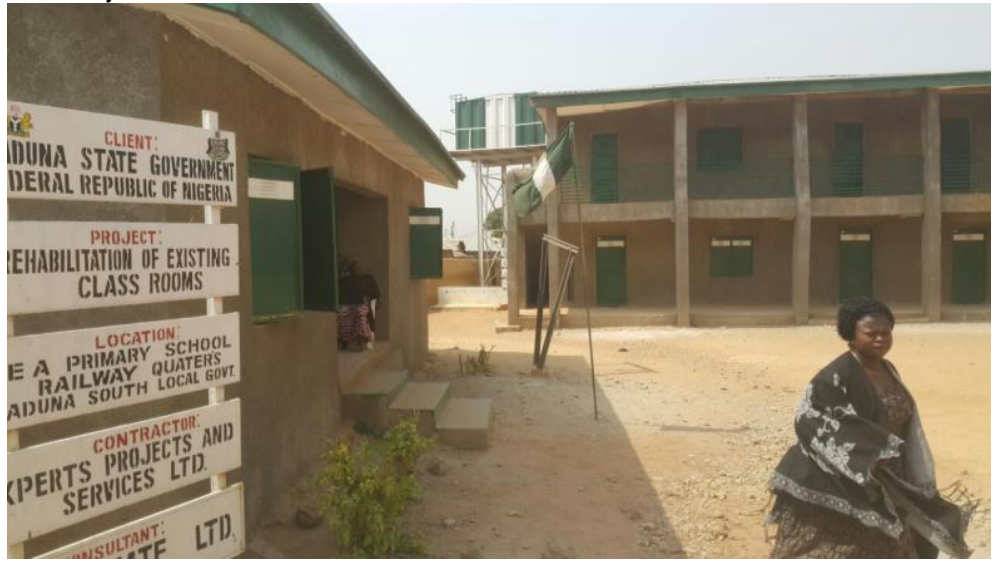

Figure 7: Rehabilitated LEA primary school in Down Quarter (Iliya, 2017)

Down Quarter community has been an isolated slum for years, where the services provided by the government known only to a public primary school and a health center facility has been abandoned and left without provision of utilities whereas regarded as low standard until recent times it was commissioned for maintenance by the state government (Danjuma, 2016).

Image of the rehabilitation of the primary school by the Kaduna state government, showing replaced doors and windows for the classrooms and also water storage system. The health facility he described as below adequate as they are short of drugs and equipment for catering for the sick until the intervention of the government after a protest that was caused by the location of a quarantine station in the community (Shehu, 2016).

In the year 2013, Nigeria had an outbreak of a contagious disease (Ebola) in Lagos state. In response to control and contain the spread of this deadly disease by the Ministry of Health, quarantine centers had to be setup around the country in the whole states in Nigeria. The Kaduna state government however saw it fit to locate these centers in the slum of Railway Down Quarter at the only health facility in the community, without paying attention to the lack of conducive factors around the community and disregard of the community (AIT New, 2013). 
The led to the rehabilitation of the clinic to a quarantine center as seen in Figure 9 by the state government with provision of beds and medication that were not available for years. Afterwards turmoil aroused in the community as it was rejected by the community with a protest. (AIT New, 2013)

According to Sahara Reporters, the Kaduna railway community rejected the decision by the state government to convert the primary health facility to an Ebola quarantine facility. The community popularly known as Railway Down Quarter close to the Kaduna junction of Nigeria Railway said it needed development of infrastructure and not Ebola that will harm the community which led to a protest by the community members. (SR, 2013)

A community member by the name Bayo Peter who called the Sahara reporter office to inform that the community had held a protest against the decision of the government to convert the school and health clinic to an Ebola treatment center. (Peter, 2013).

Mr Bayo further more expressed his anger on telephone call at the government negligence of the area for many years and demanded that the government provide infrastructure development instead of Ebola centers for quarantine, he said 'we don't have roads, good water and stable electricity and there is absolute insecurity, the government didn't remember us until the Ebola quarantine center so we can die' although there was no case of death.

According to AIT news, the residents who carried placards and protested with chants said the government had since forgotten the area which had no portable water and roads and now the only primary health center in the community is being turned to a quarantine camp by the government.

The chairman of the down quarter clinic Ibrahim Shehu and the head of the community Mohammed Musa appealed to the state government to relocate the isolation center elsewhere as it is a populated habitat and that development was the foremost thing needed in the community. Led by the outcry and protest by the community, the deputy state governor of Kaduna State was said to have paid a visit to the community personally to see the suitability of the decision the government has proposed in terms of size and area and everything that needs to be done to make it a proposed isolated area, however it was concluded that the community which is described as a slum might be a disaster if such isolation center is citied in the area. The borehole system have been contaminated due to lack of maintenance rendering it unsafe for consumption forcing habitats to resort to alternative means of acquiring good water supply in forms of wells and buying purified and treated water from different factories as shown in Fig 8. The use of wells in almost every home is now the major water supply option for settlers in this community to carry on domestic activities, however water from the wells are not suitable for drinking or consumption, treated and processed water are sold by different factories in the urban city that are delivered to this region which becomes the major source of drinkable water for the settlers of Railway Down Quarter Kaduna.

As seen in the image Figure 14, drinking water are supplied by water purifying companies from the urban city to the settlement in trucks for consumption due to the lack of clean water supply. The image shows a truck delivering treated and drinkable water to the community and by the right side there is a well covered in what looks like a metal container on a stone, pretty much every house hold have that well situated around 
the compound. The treated delivery truck however cannot move further from this position as there is no road provision to allow passage.

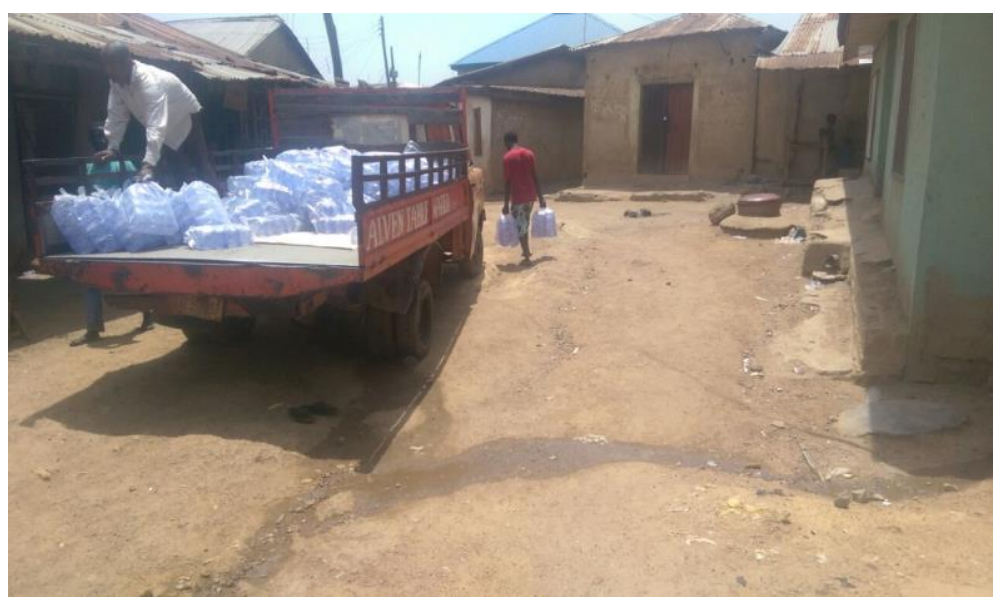

Figure 8: Alternative source of water supply (Iliya, 2017)

The government has paid little or no attention to the development of the community in past and recent times, isolating the community from the remaining part of the urban city. According to UN Habitat the community has given indications that has characterized it as a slum with the measure of adequate provision of given factors in the table below.

Table 2. Slum indicator rating source (UN Habitat, 2003)

\begin{tabular}{|c|c|c|}
\hline Characteristics & Indicator & Definition \\
\hline Access to water & $\begin{array}{l}\text { Inadequate } \\
\text { drinking water }\end{array}$ & $\begin{array}{l}\text { A settlement has an inadequate drinking } \\
\text { water supply if less than } 50 \% \text { of households } \\
\text { have an improved water supply. } \\
\text { - Household connection } \\
\text { - Access to public stand pipe } \\
\text { - Rainwater collection } \\
\text { With at least } \\
\text { 20litres/person/day available within an } \\
\text { acceptable collection distance }\end{array}$ \\
\hline Access to sanitation & $\begin{array}{l}\text { Inadequate } \\
\text { sanitation }\end{array}$ & $\begin{array}{l}\text { A settlement has inadequate sanitation if less } \\
\text { than } 50 \% \text { of household have improved } \\
\text { sanitation. } \\
\text { Public sewer } \\
\text { - Septic tank } \\
\text { - Pour flush latrine } \\
\text { - Ventilated improved pit latrine } \\
\text { The excretal disposal system is considered } \\
\text { adequate if it private or shared by a } \\
\text { maximum of two households }\end{array}$ \\
\hline
\end{tabular}




\begin{tabular}{|c|c|c|}
\hline Structural quality of housing & (1) & $\begin{array}{l}\text { Proportion of households residing on or near } \\
\text { a hazardous site. The following locations } \\
\text { should be considered as hazardous. } \\
\text { - Housing in geologically hazardous zones } \\
\text { (landslide/earthquake and flood areas) } \\
\text { - Housing under garbage mountains } \\
\text { - Housing around areas of high industrial } \\
\text { pollution } \\
\text { - Housing around other unprotected high } \\
\text { risk zones (railroads, airport, energy } \\
\text { transmission lines) } \\
\text { Proportion of households living in } \\
\text { temporary or dilapidated structure. The } \\
\text { following factors should be considered when } \\
\text { placing a housing unit in these categories. } \\
\text { - Quality of construction (material } \\
\text { used for wall, floor and roof) } \\
\text { - Compliance with local building } \\
\text { codes, standards and bylaws }\end{array}$ \\
\hline Overcrowding & Overcrowding & $\begin{array}{l}\text { Proportion of households with more than } \\
\text { two persons per room. The alternative is to } \\
\text { set a minimum standard for floor area per } \\
\text { person (i.e. } 5 \text { square meters) }\end{array}$ \\
\hline Security of Tenure & & $\begin{array}{l}\text { - Proportion of household with formal } \\
\text { title deeds to both land and residence } \\
\text { - Proportion of household with formal } \\
\text { title deeds to either land or residence } \\
\text { - Proportion of households with } \\
\text { enforceable agreements or any document as } \\
\text { a proof of tenure. }\end{array}$ \\
\hline
\end{tabular}

\subsection{Community Services}

Based on the resent interview carried out with the head of the community Mohammed Musa, residents of the Railway Down Quarter settlement have complained of the negligence of the government towards the development of the community even with promises made by different ruling government. He explained that settlers had to source means of development for themselves in an effort to get good work and healthcare as it resulted in going out of the community to get most of this services.

Due to such conditions the community has tried through community led development to improve living standards and environment by self-development (community led) by delivering alternative water supply in forms of wells were improvised, sanitation routines were also applied, construction of public refuse dumps provided. 
However the level of improvised means to sustain life, development is still required on a bigger scale. The commuinty head stated that they can only do as much to sustain their immediate environment and provide them selves with sustainable means of living in good condition but the community needs and deserves a better development scheme from the government. He added that development that is required for the community to improve living should be provided such as modern markets, better housing, good refuse disposal facility, drainages systems and roads, stating clearly that for such magnitude of development it will definitely need the involvement of the governing authority for urban development. However, it has been experienced that some slum upgrading projects have gone through the replacement of the slums with the construction of 'better houses' that has been proposed by the planner and policy makers. When bottom-up, inclusive projects are totally ignored that end with demolishment, the social structure also crushes down (Wiredu and Midheme, 2017).

Focused on the slum settlement of Down Quarter an interview analysis is taken by the community head (Alh Danjuma Mohammed) and selected community members of the working class age, providing a first-hand view of the living standards and environmental conditions of the which will focus on road infrastructure. On the account of highlighting development factors that can improve a slum community in terms of integration to the urban city and harvesting potentials of the neglected population.

It has been observed that all attention and expectations are been focused on the government to provide amenities that are beyond the financial capacity of the community to fund which raises the notion for government intervention in the slum improvement. They community have limited influence in the development plans required to uplift the living situation In Rail Way Down Quarter which has led to the need for the community to seek governmental support.

It is evident that $26 \%$ of the residents which are landlords are seeking for the provision of infrastructural amenities as they tend to be attached to the community, at the same time tenants and squatters that hold the remaining population of the community also believe that a governmental intervention is needed to improve living conditions and give value to life in this region. Although it was noted that the settlement has been involved in community led development in terms of sanitation and alternative water and refuse dump provision, the intervention of the government will be mostly needed in sense of financial capacity for development and such approach will tend to aid the sustainability of living conditions created by the community led scheme to match that of the urban city.

\subsection{Road infrastructure as a tool}

They lack of some physical infrastructures and basic amenities that improves life and gives a better living standards is a major deficiency to these settlement, few basic amenities such as clinic and primary school are available in this community but however the situation and effectiveness of their role to a community are limited due to inadequate standards and lack of maintenance which limits the potential of a settlement falling back behind in its productive capacity. Amenities provide a form of importance to a community integrated schooling systems, clean water, hospitals, drainage systems, roads etc (Figure 9). 


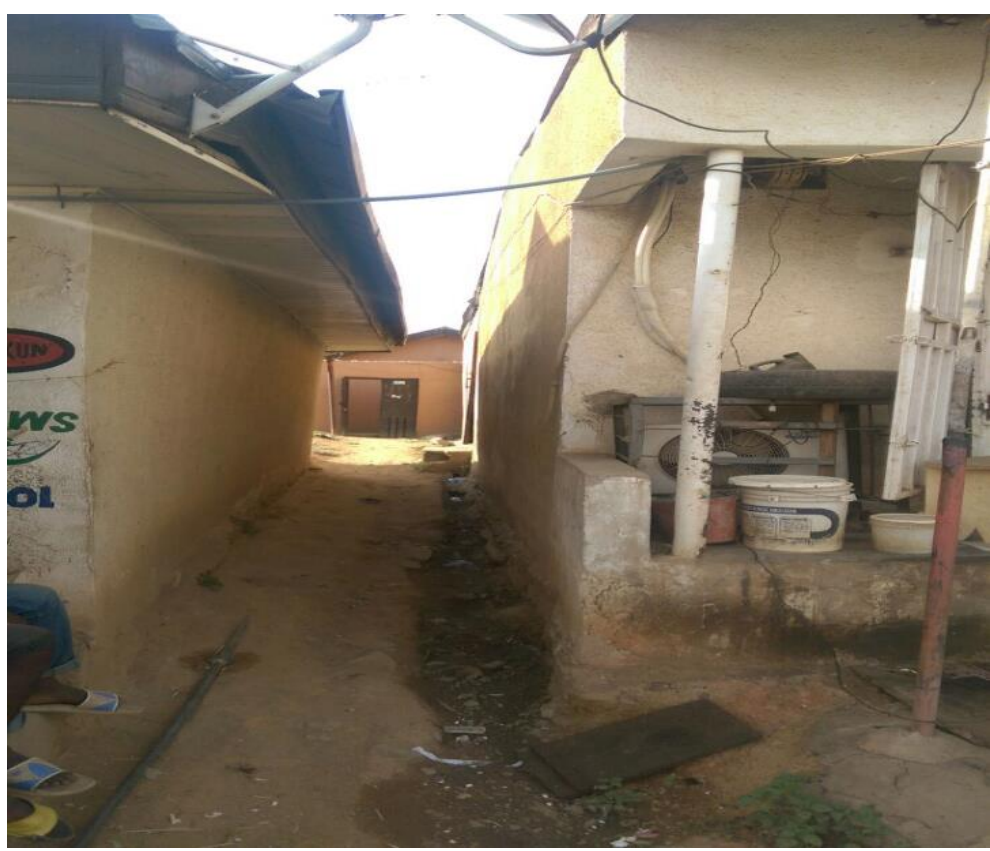

Figure 9: Walkway path (Iliya, 2017)

\section{Conclusion and Recommendations}

Throughout this research the use of slum upgrade as an effective means of solving the prevalence of slum settlements by the use of road infrastructural development as the driving tool for bring value and adequate living conditions for the urban poor is analyzed. The role of road infrastructure for slum upgrade has been discussed in 3 distinctive benefits of creating a connection and link between the urban city and slum to aid economic activities, a tool of urban planning design and also preservation of cultural heritage and history.

Urban design and spatial growth arrangement of houses along patterns provided with adequate spacing of buildings between structure and the connectivity amongst each plots, the design layout of a settlement and building type arrangement and zones, urban expansion and development, this are orientation that a made functional with the use of road infrastructure.

In the case of this thesis, evaluations have been made in respect to the government attention to prioritize the need to improve living conditions in slums or informal settlement to boost urban growth and productivity by providing development strategies that brings value to lives in the urban poor by slum upgrade through road infrastructure.

In this paper conceptual importance of road infrastructural development can be evaluated as a key and major element in the transformation of informal settlement. The idea of road infrastructure attracts other progressive attributes as a structure that carries along most infrastructural developments. As a developing country, Nigeria is experiencing an economic reform and development process in the urban cities and the use of road infrastructure comes with conclusions as: Sustainable housing environment 
of man and his immediate living environment is a concern to identify with, which brings about the emphasis of physical component for adequate living standards. The environment and surroundings that deals with space provided for conducive conditions for man sustainability can be introduced with the development of road infrastructure. The provision of amenities such as pipe borne water, refuse dumps, electricity, and spacing in between building, street light, drainage and postal address are basic benefits that a slum lacks. The development of road infrastructure brings about possible and easier development of other amenities mentioned above for health awareness, energy efficiency and ecological sanity. Moreover, economic and cultural progression can be influenced by the use of road infrastructural development as a medium of slum upgrade creates a link that connects the urban city to the slum settlement granting access to goods and services permitting a commercial bond. It also provides movement of people from the slum to the urban city making it possible to afford housing according to the socio economic class.

In the case of Railway Down Quarter, Kaduna, it can be said that the sustainable rehabilitation of informal settlement is a good approach in improving urban city development, considering that Kaduna placed a part in the history of Nigeria's urbanization and also had the initial master plan of the city organized by the colonial expatriates. Prevention of urban city decay and wide spread of organized housing layout should be maintained and developed further given considerations as follows. Firstly government must accept that the illegal nature of the informal settlement and the need to provide for the settlement to have essential services as it is the government obligation to provide such. Identifying this settlement and providing land tenure to the habitant and extending basic services with the use of road infrastructure to these areas. Denying services does not lead residents to abandon these areas rather it forces them to adopt additional illegal practices to meet their basic needs.

\section{References}

ACT Urban Service, (2012). Design Standards for Urban Infrastructure. Retrieved December 24, 2016 from www.tams.act.gov.au/data/assets/pdf file/0010/396856/ds02 roadplanning.pdf

Adesanya, A. O. (2011). Mass Transportation and City Sustainability. In Conference of the NITP/TOPREC mandatory continuing professional development, titled The Challenges of Transportation in Nigerian Cities'. D Rovans Hotel, Ibadan, 27th $-28^{\text {th }}$ July.

Afrol News (2003). Environmental cleanup brightens up Lagos slum. Retrieved June 12, 2016 from www.afrol.com

Anyanwu, J. C. et al. (1997). The Structure of the Nigeria Economy (1960-1997). Onitsha, NG: Jounee Educational Publishers Ltd.

Arimah, B. C. (2001). Slums as expression of social exclusion: explaining the prevalence of slums in African countries, Paper presented at United Nations Human Settlement Programme, held at Nairobi, Kenya.

Badejo, B. (2011): Transportation: Removing the Clogs to Nigeria's Development. Lagos, NG: Anchorage Press and Publishers.

Bremer, J., Bhuiyan, H. (2014). Community-led infrastructure development in informal areas in urban Egypt: a case study. Habitat International, 44. $258-267$.

Cities Alliance (2016). Cities without slum communities in developing countries: A study on Ohafia, Nigeria. Cities, 26 45-57.

Eziyi O. (2009). Community-led infrastructure provision in low-income urban communities in developing countries: A study on Ohafia, Nigeria p. 126. 
Fernandez R. F. (2011). Physical and spatial characteristics of slum territories vulnerable to natural disasters. Les Cabiers de l'Afrique de l'Est. 44, 56-70.

FGN (2010). Nigeria Vision 20:2020 Policy Document. Lagos, NG: Government Press.

Filani, M. O. (2003). Advancing the cause of private participation in the road transport sub-sector in Nigeria; paper delivered at the 10th anniversary celebration of the $A B C$ transport held Ikeja on the 14th May.

Ibem, O. E. (2009). Community-led infrastructure provision in low-income urban communities in developing countries: A study on Ohafia, Nigeria. Cities 26(3):125-132.

Jean-Claude, B. (2006). Slums and urban development: questions on society and globalization. Retrieved July 7, 2016 from http://infoscience.epfl.ch/record/128245/files/Slums.pdf

John, M. (2013). Slum upgrading and urban governance: case study in three south east Asian cities. Habitat International 39.162-169.

Jones, P. (2017). Formalizing the informal: Understanding the position of informal settlements and slums in sustainable urbanization policies and strategies in Bandung, Indonesia. Sustainability 9, 1436.

Maren, M. D. (2014). Local and community driven development approach in the provision of basic facilities in Jos, Nigeria. Cities 39, 99-108.

UN Habitat, (2012). Streets as tools for urban transformation in slums: A Street-Led Approach to the citywide slum upgrading. Retreived September 17, 2016 from www.unhabitat.org

United Nations Human Settlements Programme (2003). The challenge of slums: global report on human settlements. London, UK: Earthscan Publication ltd.

Wiredu, E.Y.D. and Midheme E. (2017). Slum upgrading in developing countries: lessons from Ghana and Kenya. Ghana Journal of Geography 9(1), 88-108. 